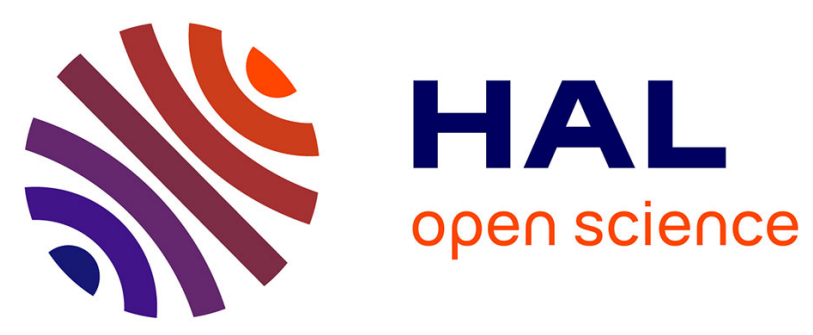

\title{
Participatory Action Design Research in Archaeological Context
}

\author{
Barbara Rita Barricelli, Stefano Valtolina, Davide Gadia, Matilde Marzullo,
} Claudia Piazzi, Andrea Garzulino

\section{To cite this version:}

Barbara Rita Barricelli, Stefano Valtolina, Davide Gadia, Matilde Marzullo, Claudia Piazzi, et al.. Participatory Action Design Research in Archaeological Context. 4th IFIP 13.6 Working Conference on Human Work Interaction Design (HWID), Jun 2015, London, United Kingdom. pp.192-211, 10.1007/978-3-319-27048-7_14. hal-01371800

\section{HAL Id: hal-01371800 https://hal.inria.fr/hal-01371800}

Submitted on 9 Nov 2016

HAL is a multi-disciplinary open access archive for the deposit and dissemination of scientific research documents, whether they are published or not. The documents may come from teaching and research institutions in France or abroad, or from public or private research centers.
L'archive ouverte pluridisciplinaire HAL, est destinée au dépôt et à la diffusion de documents scientifiques de niveau recherche, publiés ou non, émanant des établissements d'enseignement et de recherche français ou étrangers, des laboratoires publics ou privés. 


\title{
Participatory Action Design Research in Archaeological Context
}

\author{
Barbara Rita Barricelli ${ }^{1}$, Stefano Valtolina ${ }^{1}$, Davide Gadia ${ }^{1}$, \\ Matilde Marzullo ${ }^{2}$, Claudia Piazzi ${ }^{2}$, Andrea Garzulino ${ }^{3}$ \\ ${ }^{1}$ Università degli Studi di Milano, Dept. of Computer Science \\ Via Comelico 39/41, 20135 Milan, Italy \\ \{barricelli, valtolin, gadia\}dedi.unimi.it \\ ${ }^{2}$ Università degli Studi di Milano, Dept. of Cultural Heritage and Environment \\ Via Festa del Perdono 7, 20122 Milan, Italy \\ matilde.marzullo@outlook.com, claudia.piazzi@hotmail.it \\ ${ }^{3}$ Politecnico di Milano, Dept. of Architecture and Urban Studies \\ Via Bonardi 3, 20133 Milan, Italy \\ andrea.garzulino@polimi.it
}

\begin{abstract}
This chapter presents an overview of the results of an interdisciplinary collaboration between several domain experts in the frame of archaeological projects. Since 2001, different independent interactive systems have been co-designed, developed, and tested on the field, in the frame of the "Tarquinia Project" carried out since 1982 in the ancient Tarchna, one of the foremost Etruscan cities, by the Università degli Studi di Milano. The adoption of a semiotic approach to a participatory action design research process with the involvement of domain experts led us to a better understanding of the main characteristics but also the challenges of the archaeological practice and helped us to apply technology in a better and efficient way. The currently undergoing work is focused on the codesign of a cloud of services aimed at integrating all the tools into a bigger framework to support the archaeological practice in a more pervasive way.
\end{abstract}

Keywords: Digital humanities, Archaeology, cloud of services, domain experts, co-design, interdisciplinary teams, HWID, participatory action design research.

\section{Introduction}

The reconstruction of a historical and cultural context in Archaeology is a very complex activity where most of the times the collaboration among several scientists from different domains (e.g. geography, geology, architecture, chemistry, anthropology) is needed. Interdisciplinarity in Archaeology aims at studying excavation sites by considering not only the local excavation activity but also by reconstructing the entire historical and cultural context. To support such a comprehensive work, technology can be

adfa, p. 1, 2011.

(C) Springer-Verlag Berlin Heidelberg 2011 
used in several ways to design and realize innovative digital humanities tools. Today, technology is widely adopted in Archaeology (e.g. Geographical Information Systems (GISs), orthophotos, Digital Terrain Models, 3D models. However, despite the use of such variety of technologies, one of the main time-consuming activity for the researchers working on excavation sites is the constantly look up for relationships among the retrieved archaeological evidences and the geographical, architectonic, and anthropological data collected. Another important issue is domain experts' knowledge, both in terms of content and structure, is highly dependent on professional or individual practice and this makes the collaboration among all the stakeholders even harder and critical. All this complexity leads to an overwhelming production of digital documentation that represents the archaeological context from different points of view: landscapes, stratigraphic layers, and artefacts - e.g. mobile findings (organic and inorganic) and architectonic structures. To build a comprehensive knowledge on such extensive mole of data and to integrate the information that stems from it is nearly impossible without the support of further technological efforts.

In the last 14 years, the two departments of Computer Science and Cultural Heritage and Environment of Università degli Studi di Milano (in particular with Giovanna Bagnasco Gianni, Director of the excavation site of Tarquinia) and the Department of Architecture and Urban Studies of Politecnico di Milano, actively collaborated to develop tools and methods for supporting the archaeological practice in a very pervasive way: on the field (excavation site), in warehouse for data storage and catalog operations, and during the study and collaborative analysis time (back at the University). This collaboration has led all the participants to developer higher awareness of the potentials and challenges that such an interdisciplinary research field may encounter. During this collaboration, the IT in archaeology has positively influenced the archaeological practice of our interdisciplinary group. We have drawn on a wide range of expertise to carry out work in the archaeological analysis, assessment \&and evaluation, topographical and geophysical survey, historic buildings recording and community research. Specifically, the sites of the Etruscan cities of Tarquinia and Cetamura are the benchmark of an all-comprehensive investigation upon which multiple disciplinary areas applied to Archaeology are converging, such as Geology and Natural Sciences, Archaeometry, Architecture and Computer Science. Thanks to this cooperation, the work done in the field of Etruscan Studies is significant and internationally recognized [2][3][9]. This chapter presents both the work done so far and the one that is still under development and that is aimed at furtherly explore new technological solutions to support archaeological practice in all of its aspects.

Section 2 presents the semiotic approach we adopt for the co-design of the tools by involving the domain experts in choosing the more suitable interaction style and visual language to use. In Section 3, we give an overview of the archaeological practice, how technology is used to support it, and the relationship of our research work within the frame of Human-Work Interaction Design (HWID). The tools developed so far are presented in Section 4, while in Section 5 we illustrate the currently ongoing work focused on the creation of a cloud of services for integrating all the existing interactive tools. 


\section{Semiotic Approach to Co-Design with Domain Experts}

The complexity and the expanding scale of most collaborative projects that take place in these years require more comprehensive knowledge than any single domain expert can possess. Experts in different disciplines have to share their specialized knowledge, skills and practices in order to work collaboratively and reach common goals. The design of a common knowledge management system to support such collaboration needs to balance different requirements. On the one hand, the information and data need to be organized according to common, generic schemes or ontologies in order to allow the sharing of data and results. On the other hand, different domain experts need to have access to content structured in a way that fit their specific interest and professional practice and expectations. It is however challenging to be able to catch the right way to structure the content has to be organized. However, these structures are often not explicated, since they are tacit knowledge, which users possess and use to perform tasks and to solve problems, yet they are unable to express verbally and might even be unaware of.

The domain experts perform their activities, take their decisions, read and create documents using implicit information, articulatory skills and tacit understanding, which derive from their individual and professional experience and practice. All these factors result in determining what Nardi and Engeström [29] call invisible work. Implicit information - e.g., information embedded in spatial displacement, physical appearance of the text, and graphical elements in a document - is often significant only to users who possess the right knowledge and background to interpret it. Practitioners are often more able to act in a specific way rather than to explain how and why they act so [37]. Therefore, domain experts from heterogeneous technical and scientific communities involved in co-design processes often face cultural clashes and communication gaps [39][40] due to their different backgrounds and ways of reasoning, solving problems, and making decisions.

Our research work aims at resolving the contradictory requirements that arise in a co-design process with an interdisciplinary team. It addresses the question of how to conceptualize and design knowledge management systems supporting collaboration across multiple heterogeneous domains and at the same time providing each participant with tools that respond to their specific need and expectations. This means to design user interfaces and interaction processes that enable the uses to access shared knowledge bases, flexible enough to be tailored to fit into different domain experts' practices. To this end, an approach framed in computer semiotics [13] is adopted: user interfaces are studied as compositions of graphic elements that reflect their end users' expertise, their reasoning patterns, and their work practices [15][14]. Such tailoring is a response to the weaknesses of a "one fits all" idea of interactive system design. In fact, the interaction with a same user interface can trigger in different end users very different semiosis processes leading to different meanings assignment, and consequently to different interpretation results. When using an interactive system, a significant portion of the information conveyed by the system is implicit information [11], i.e. embedded in the actual shape of the elements displayed and in the visual organization of the overall user interface. For this reason, it is of fundamental importance that 
knowledge management systems are provided with user interfaces and interaction styles that have to be flexible enough to adapt to the different professional practices they have to support. A design strategy of this kind is what we apply to the archaeological field, and implies a long-term planning of development and testing that fits in a star software life-cycle [23][7]. From our experience in this field, such a complex environment calls for evolutive and never-ending process of design and development in that the use of the tools very often suggests new uses: the separation between design time and use time becomes fuzzy and these two stages need to be bridged into a unique "design-in-use" continuum to create open and continuously evolving projects. Therefore, according to [10] we can say that the tools designed and developed with this approach are always in a "perpetual beta" version.

Peculiarity of the star software life-cycle is the central role that is played by evaluation. In the years, to study the validity of the tools and of the semiotic approach we adopted several techniques: ethnography (shadowing), interdisciplinary workshops, focus groups, structured/unstructured interviews and questionnaires, collaborative design of paper prototypes (e.g. CARD, PICTIVE [28]), and End-User Development (EUD) [16][26] applications for interfaces and systems design. . Moreover, we paired cognitive engineering methods of usability evaluation with those defined by semiotic engineering that are directed to investigate the so-called "communicability" of an interactive system. This allowed us to understand if the communication between the different domain experts was effective and efficient and if user interfaces and interaction style responded correctly the end users expectations and needs.

\section{HWID: Archaeological Practice and Technology}

The archaeological application domain is characterized by strong social and organizational factors and the successful introduction of technology and interactive systems, designed according to our semiotic model, has proved once more the validity of the Human Work Interaction Design (HWID) framework [31].

\section{Theories and Models.}

We apply our semiotic approach (presented in Section 2) to the archaeological domain and put in practice a participatory action design research [8]. We follow all the five stages: 1) analysis of the domain with open problems identifications; 2) detection of opportunities and open challenges to be addressed with a participatory approach; 3 ) actual design with the use of prototypes and recurrent usability evaluations; 4) measurement of impact evaluation with the active involvement of the members of the interdisciplinary team on the field; 5) generalization of the outcomes in a model that reflects the expertise we developed in this field [41]. This chapter focuses mainly on the first three stages of our research. Presenting the results of evaluation of the tools is not in the scope of this chapter: they can be found in our previous publications cited in Section 4.

Environment and Context. 
Environment and context play a very important role and strongly influence the archaeological practice in all its aspects. Particularly challenging are the distributed nature of the work (on excavation site, in storage rooms, in laboratories, in universities), the interdisciplinarity with the involvement of experts in different domains, and the International collaborations that highlights the existence of often radically different methods, use of different languages (not only in terms of spoken language but also visual notations) and remote interaction (most of the time asynchronous and written).

\section{Human Work.}

The data collection activity that archaeologists perform in their practice mainly follows two families of methods: non-intrusive and intrusive.

Non-intrusive methods include the analysis of aerial photography for landscape alterations, use of ground-penetrating radar to find buried anomalies, and the systematic, controlled collection of materials from surface contexts.

Intrusive methods include shovel testing (units $40 \mathrm{~cm}$ on a side), test units (1 or 2 meters on a side) or excavation blocks (anything larger than 2 meters on a side). Archaeologists analyze these remains to determine their original purpose and effective role within the overall context of a given site. In turn, archaeologists attempt to understand cultural processes and behaviors, with the primary goal to interpret how and why cultures evolved over time.

\section{Interaction Design.}

Several technological approaches can be adopted in order to support archaeologists in their analysis and interpretations. For example, mobile or Web applications can be used for collecting information from an archaeological site, while 3D modeling, processing, and visualization technology can be adopted for helping in generating very precise three-dimensional models of any archaeological context, perfect replicas of how the soil layer looked like the exact moment before its removal and the position of artefacts and structures. At the same time, technology such as laser scanners, high-precision survey strategies or systems for managing orthophotos, Digital Terrain Models (DTM), geo-spatial information, and LiDAR data, represent new solutions for studying landscape and monuments from an archaeological, geological, and architectural point of view in order to reconstruct the territorial conformation and its elements. Of course, it is nearly impossible to keep track of every category of documentation produced during the fieldwork without the support of technological solutions and without taking into consideration that the organization structure of the produced documents highly reflects the domain experts' background, knowledge, and expertise. Although there is a growing use and demand for advanced technologies in archaeological resources management, there is still an inherent lack of innovative solutions and methodologies for documenting, combining and managing the vast data sets generated by these technologies and for presenting them to domain experts in effective ways. At the same time, no platforms are available so far for integrating all these data, fostering their dissemination between scholars and researchers through a correct management of the cultural objects contained in the original sources. 


\section{The Tools}

In these years, we co-designed and developed tools for responding to the main needs that arise during all the phases of archaeological (interdisciplinary) work. The tools we co-designed and developed so far can be categorized according to the archaeological activity that they are meant to support: excavation data management, stratigraphic analysis, 3D reconstruction of tombs, geographic analysis, and decipherment of non-verbal markings. In what follows, we present the tools following this categorization.

\subsection{Excavations' Data Management}

In archeological knowledge creation and dissemination the information overload plays one of the most critical roles. At the beginning, the collaboration between the departments of Computer Science and Cultural Heritage and Environment of Università degli Studi di Milano, took the first steps towards the digitizing of their archaeological collections. Before that, the main problem was that archaeologists acquired data in manual way, without any strategies based on computer databases for storing, making future research difficult. Undocumented changes in data and loss of original organizational strategies could further compromise accessibility and integrity. Based on our experiences in research analysis, we proposed specific methods to make archaeological data management as flexible and useful as possible.

Another problem was that the large quantity of digital material generated by each team (archaeologists, architects, geologists, chemists) was incomplete, inconsistent and often hard to access. Moreover, very often, the teams are geographically distributed and the communication among all the stakeholders becomes challenging. As a possible solution to these problems, we identified a strategy based on a holistic approach for knowledge representation, designed according to widely held community understanding.

We designed and developed an application called "Tarchna DB" (See Fig. 1. ) that is meant to collect the categories of evidences predetermined by the archaeologists in order to classify the multifaceted aspects of the findings that are almost always fragmentary (e.g., architectural structures, layers of ground, pottery, different kinds of equipment) [17]. Several problems arise from the integration of different archives, and one of the most important issues is the need of establishing a common knowledge representation to be used to exchange data among all the stakeholders involved in the collaboration. Specifically, our model allows to organize archeological data in a way that is more natural for archaeologists to use. It relies on an ontology (i.e., "a description of the concepts and relationships that can exist for an agent or community of agents" [18][19]) organized into two levels, and on specialized services for managing it. The top level of the ontology presents a view that is suitable for non-computer experts while the bottom level is suitable for interacting with the computing infrastructure. The toplevel ontology exploits the concept of a standard ontology of cultural heritage (CIDOCCRM [12]) for producing a representation of concepts and relationships suitable for archaeologists. The information core also supports the ability to perform information retrieval and to browse the existing knowledge. This approach uses the knowledge base 
as a semantic access point to the information that can then be retrieved from databases federated by means of the ontology schema. The knowledge representation model at the base of our framework uses an ontological schema, representing a specific cultural context, as a semantic access point to different types of data sources using suitable mapping strategies.

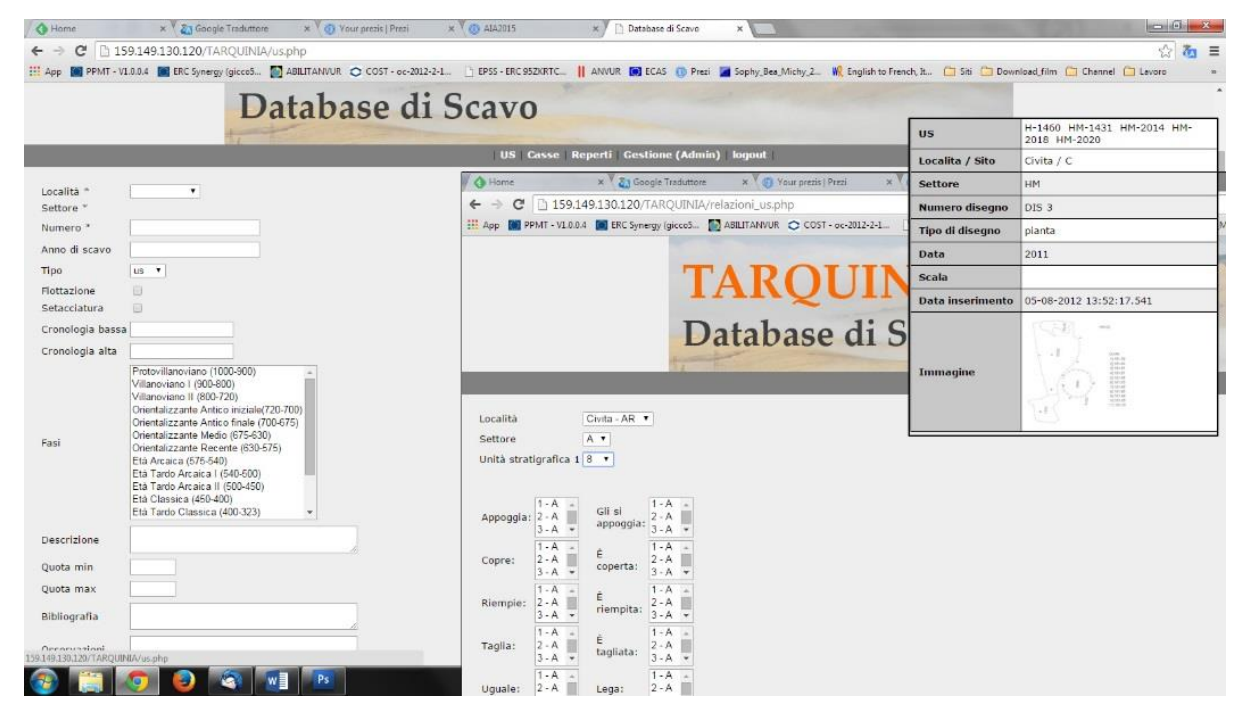

Fig. 1. Tarchna DB system is used for archiving all archaeological data resulting from the excavation campaigns in Tarquinia.

\subsection{Stratigraphic analysis}

Beyond archiving, managing and studying the findings collected during archaeological excavations there is a wide research area that is focused on information visualization. The way in which the information is represented can deeply impact how it is understood and used [22].

In particular, in Archaeology graph visualization systems can face the problem of facilitating the exploration and analysis of a vast amount of data by means of visual methods and tools able to support needs of a wide range of different research communities involved in the study of an excavation such as archaeologists, architects, geologists, chemists, and biologists. Information visualization strategies are applied for assisting domain experts in the examination and interpretation of the stratigraphy of excavation sites, and identifying both natural and cultural strata.

The British archaeologist Edward Cecil Harris in 1973 invented the Harris Matrix method that is used to graphically represent stratigraphic sequences in a graph-based form [21]. Before the design and development of a dedicated interactive system, Harris' method was used to realize the graphs on paper with the following procedure.

During the excavation phase, each time that a stratigraphic unit is detected, the archaeologists filled in a proper paper form to keep track of its characteristics. A type 
identifies each unit: layer stratigraphic unit (US) - of natural origins - or structural stratigraphic unit (USS) - a manufactured artifact (e.g. a wall). After this first categorization, the number of the box in which the findings retrieved in the unit were recorded, together with the maximum and minimum altitude of the unit and a description of the unit itself. In the rest of the form, the relationships among the unit and other units were made explicit.

Three types of relationship could exist: active, passive, and neutral. Active relationships are a) covers, b) fills, c) leans, and d) cuts; passive relationships are a) is covered, b) is filled, c) relies on, d) is cut; neutral relationships are a) is equal to, and b) binds. Once the form was completely filled in, the archaeologists represent the stratigraphic unit in a drawing on paper that was then used in successive data analysis. At the end of the excavation campaign, all this material was collected and studied for creating the correspondent Harris Matrix. The resultant Harris Matrix enabled the archaeologists to determine the chronology of the various units (an example is shown in Fig. 2. The rectangles represented the stratigraphic units, while lines are used to indicate the existing relationships among them (e.g. "copre" means "covers", "taglia" means "cuts", "riempie" means "fills"). After the drawing was complete, the archaeologists tried to determine the historical age to which the stratigraphic units belong to. After this, the next activity is the detection of the overlays, i.e. logical levels that are constituted by the stratigraphic units that belong to the same historical period.

This entire procedure was performed using paper documents and therefore the quantity of the material related to an excavation site tended to grow very fast and its consultation became extremely difficult. Moreover, the more stratigraphic units are added, the more the Harris Matrix to be drawn became big and exponentially complicated to be modified and extended. Given these difficulties, the main disadvantages that came from the use of a non-digital approach was the impossibility of properly diffuse the knowledge that was gathered through the archaeologists' activity performed on the field and the difficulty of keeping the Harris Matrix documents up to date. In fact, to give permissions to modify the Matrix to more than one person is not so simple, and new problems arise when many people have access and modification permission to the same resource.

Our work aimed to design and development an innovative visualization tool named ArchMatrix [6][40] able to efficiently store and manage excavation site knowledge so that the data may be visualized and queried in a graph-based environment, and to offer a visual representation of archaeological assets and their relationships in order to support intuitive and useful explorations. To support real-world knowledge construction and decision making by means of a Harris Matrix, the most important challenge was to realize a system able to meet real needs of domain experts in handling content and structures that fit their domain-specific interests and practices. In this context, the paradigm of the map as a support for knowledge organization has been used. This is based on the principle that maps can also be used to spatially represent knowledge about systems and subjects. In fact, the Harris Matrix system uses a map-based representation to show the stratigraphic units, the relationships between them and other related information. ArchMatrix is implemented as a Web application which uses a graph visuali- 
zation as tool for knowledge assessment. Through a Harris Matrix and its nodes, relationships and conceptual structure, ArchMatrix offers a solution for collaborative managing shared knowledge among experts of different domains. A screenshot of ArchMatrix is given in Fig. 3.

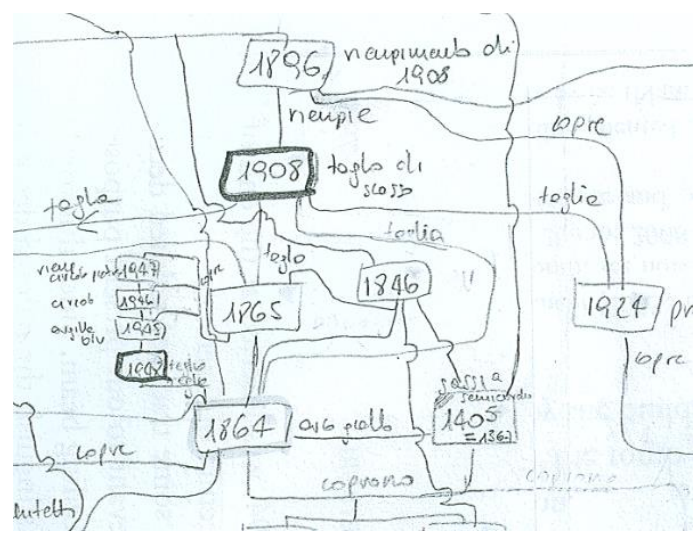

Fig. 2. A fragment of a Harris Matrix.

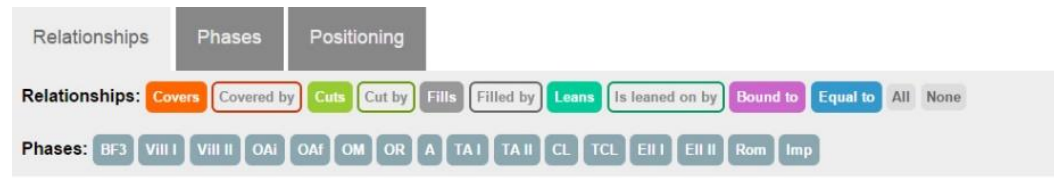

+ - reset zoom

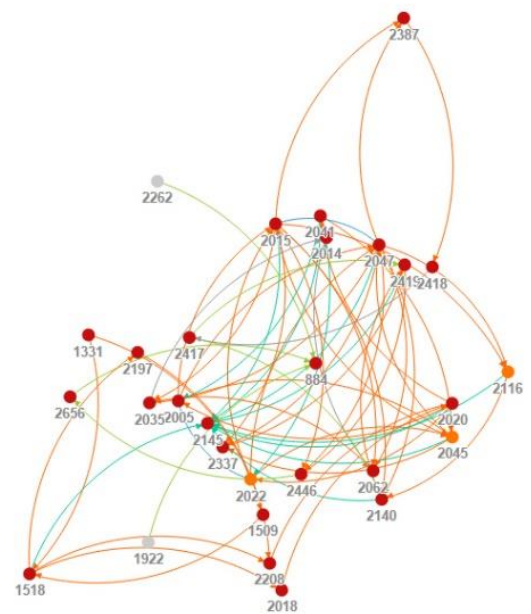

Fig. 3. A screenshot of ArchMatrix system. The nodes in the graph represent the stratigraphic units while the edges are the relationships that exist between the nodes. The color of an edge depends on the type of relationship that it represents. 


\subsection{D Reconstruction of Tombs}

During the last decade, Virtual Reality (VR) technologies have been the focus of intense developments and applications, mainly because of the increased availability of dedicated cheaper hardware platforms and display technologies. These are some of the domains with respect to which VR techniques have an important potential for the deployment and manipulation of 3D materials, images, sounds, and datasets in order to provide a richer and visually-appealing content presentations. Consider as an example the Archaeological domain. Using VR techniques, heritage which no longer exists, or which must be handled with special care in order to be preserved, can be virtually reconstructed and presented to an audience from perspectives which go beyond what it is possible in the real world. Not only, VR can be used to provide innovative strategies for studying and analyzing features of existing monuments or ancient populations, or for visiting and exploring collections, which elements are physically located at different museums or cultural institutions, and so forth. Although those solutions are very appealing and today many museums and cultural institutions have started investing in such direction, VR solutions are still not widely adopted as a mean for archaeological study and dissemination. The main reason is the high cost of content production and the low reusability and poor portability of infrastructures. In addition, researchers and users are quite sophisticated and have high expectations; therefore, they are not interested in simple walk-through applications. Instead, they ask for formative and interactive experiences that they can personalize on the basis of their preferences.

We adopted this innovative strategy in the field of the VR applied at the Archaeology in the design of the virtual reality simulation of the Etruscan Necropolis of Tarquinia (UNESCO site since 2004) that has been realized not only for dissemination purpose but also for supporting archaeological analysis [33]. The site is an outstanding testimonial of the Etruscan culture, in which so far more than 6200 tombs carved in the rock were discovered. Among them, around 140 are extraordinarily painted, and many hundreds more present traces of paintings [27]. The earliest tomb dates from the 7th century B.C.. Most of them are constituted by a room only, while others are more articulated. Currently, 64 tombs are accessible: some of them are protected by glass and always visible, some others are open for visits in rotation, whereas many others are kept closed. Most of the painted tombs were discovered in the second half of 19th century. Across the centuries, many paintings were detached from the walls and then lost or destroyed, while others are currently not visible due to the fading of the original colors. In these cases, our knowledge of those paintings is mainly based on descriptions and paintings made by artists and scholars in $17^{\text {th }}, 18^{\text {th }}$, and $19^{\text {th }}$ centuries. Cultural Heritage experts rely in a relevant way on digital images acquired inside the tombs: natural light is not present (or it is limited to some parts of a small number of tombs whose entrances are adequately oriented), while artificial light is often not adequate to achieve a full and detailed observation of the full painted walls. Therefore, many samples of each area that compose the inner parts of the tombs are collected through several accurate sessions of photographic acquisition. The images are then processed to enhance details, merged using adequate techniques in order to allow an ensemble analysis of the painted 
walls, and eventually stored in a multimedia database for supplemental studies and for dissemination.

3D models allow to investigate the morphology of the architecture in its completeness and to analyze all the parts of the architecture in detail and as a whole. The VR reconstruction of the Necropolis is based on a modular approach, in order to handle a site composed by a large number of independent tombs. The $3 \mathrm{D}$ visualization of the tombs is based on a first-person point of view approach, and the users can rotate their view and eventually move inside the environments. Moreover, we have introduced the possibility to visualize the already mentioned drawings and paintings as superimposed on the original walls (See Fig. 4).
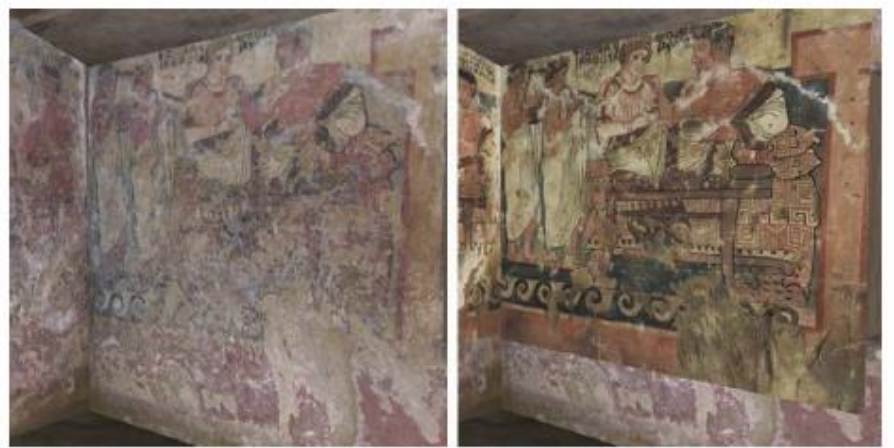

Fig. 4. A screenshot of the reconstruction of a tumb with a painting superimposed on the original wall.

\subsection{Geographic Analysis}

Over the last two centuries, several more or less scientific archaeological and restoration projects have been carried out, and their merits and defects are still visible today. Given the complexity, the extent and the prolonged use of an excavation site, researchers need innovative tools for deeper understanding the site and for comparison with archaeological sites in the vicinity. Three-dimensional tools are useful solutions for facilitating the investigation of the sites in their landscape setting, for example on a large scale, exploiting the possibilities offered by LiDAR [35] (Light Detection and Ranging) survey. The cartographic results thus obtained can be used as metrically correct basis for the positioning of all the archaeological sites, thus enabling their comparison and analysis. Precisely because of the prolonged use of sites and their extent, the creation of reconstructive models can be crucial for our understanding and dissemination of the results to non-specialist as well as professional audiences.

A LiDAR survey, by means of an aerial recognition, has been carried out in the area of the Civita of Tarquinia in 2010 (see Fig. 5). The Figure shows how it is possible to pre-process the LIDAR image on the left for identifying buildings/structures, terrain skin, and vegetation, in order to identify only archaeological evidences such as ruins, 
territorial presence/absence, candidate archaeological items (LIDAR image on the right).

The application of laser scanning and LiDAR technology in an archaeological environment has rapidly established abroad and recently in Italy.

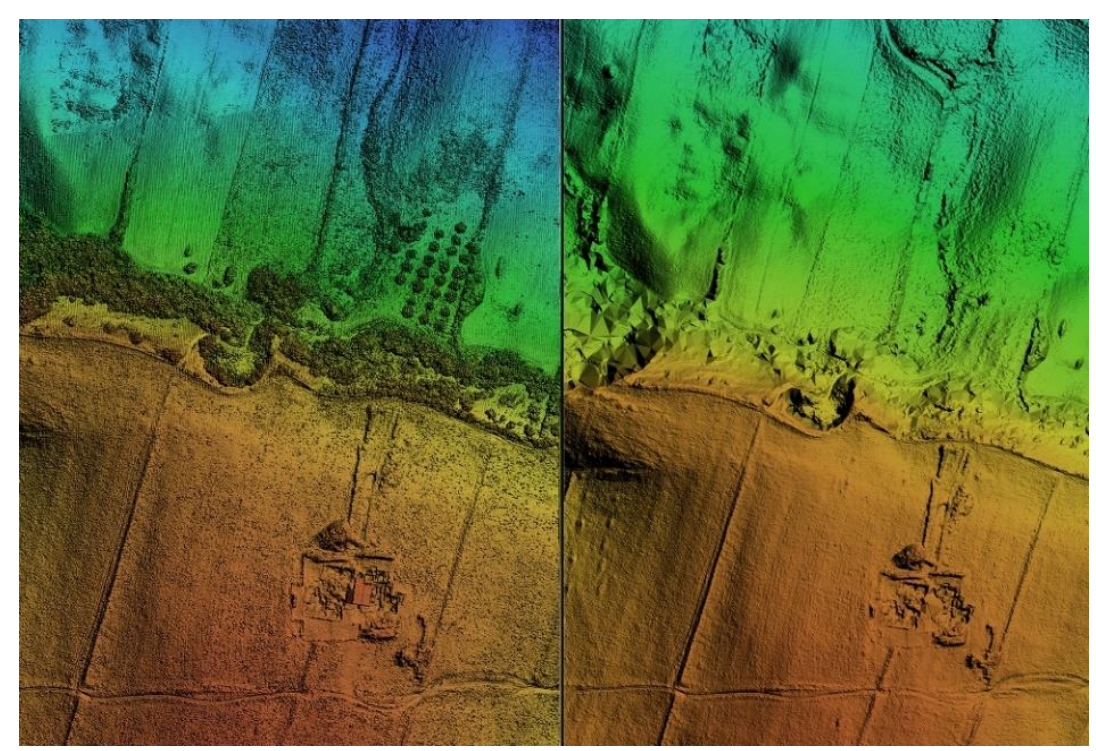

Fig. 5. A LIDAR 3D reconstruction example.

The first output of the aerial survey appears as a dense cloud of points (defined by planimetric coordinates, elevations, intensity, number of returns and other parameters) arranged along the scanning pattern of the instrument. From such raw data, it is possible to reconstruct the territorial conformation and the related elements (vegetation, ground, structures, etc...). Subsequent digital processing produces different elaborations: Digital Elevation Model (DEM), Digital Terrain Model (DTM), high-resolution orthophotos, and elaborations based on intensity and number of returns. These elaborations are recorded in a Geographical Information System to catalog and to systematize the existing documentation about historical cartography and scientific and literary information, in order to grasp persistence and consistence of meaningful traces of the ancient territorial occupation. Therefore, an exhaustive georeferenced documentation, gathered in a diachronic and synchronic atlas endowed with each punctual or areal data, is available in order to compare and contrast the palimpsest of settlement. After the analysis, through the use of metric models previously created, a 2D-3D cartographic archive is improved to permit the geo-referenced localization of every data set on the territory, giving the possibility to interface information through a shared platform. Such work results useful tools to identify and analyze settlements and to assess cause-effect relationship between their architectural and urbanistic features and the terrain morphology. 
The GIS cartographic database, with all its interfaces (geological, historical, archaeological), makes it possible to read permanent signs and assess the land use in historical cartography.

\subsection{Non-Verbal Markings Collaborative Decipherment}

In the frame of IESP (International Etruscan Sigla) Project, we co-designed and developed a system aimed at supporting the collaborative decipherment of Etruscan sigla (non-verbal markings) found on objects discovered in different digging sites distributed in the Mediterranean area. The project involved archaeologists from Università degli Studi di Milano and Florida State University, giving us the possibility of studying the two different approaches to archaeological practice, both in terms of methodology and terminology used. A screenshot of IESP system is given in Fig. 6.

Unlike what happens in deciphering verbal languages, in the case of non-verbal signs it is possible to study their elements from a graphical point of view and to apply similarity techniques to support the human interpretation activity. As to Etruscan language, thousands of examples of non-verbal markings exist. Typically, they are referred to as graffiti, a term that is found to be inadequate. Instead, the Latin word siglum (pl. sigla) - corresponding to the Greek one sema (pl. semata) - should be used. Etruscan sigla, composed by one or more symbols, numbers or letters, are dated from around $700 \mathrm{BCE}$ to the first century BCE. They are incised, painted or stamped on different types of objects; e.g., pottery weights, spindle whorls, sarcophagi, burial urns, roof tiles, architectural terracotta, boundary stones, stone walls, and a wide variety of artefacts in bronze (axes, fibulas, helmets, knives, razors, sickles). The contexts in which the objects have been found include cemeteries, sanctuaries, ports, artisans' quarters and habitations - all spheres of Etruscan life and afterlife. The study of Etruscan sigla is aimed at assessing the real consistency of archaeological indicators according to a deductive method that takes into account a dialectic comparison between the ideas of function and role [20][2]. The function of an object could be in fact be deduced by its shape. On the other hand, the role of the same kind of object can be determined differently on the basis of the conditions of their discovery and from the comparison of iconographic sources. This means that the meaning of sigla can change widely according to the context in which they have been discovered. An example is the case of V-shape siglum that can be interpreted as a number 5 or letter $U$. The same uncertainty exists in interpreting a siglum formed by a cross inscribed in a circle: it could mean the Greek letter theta or could be the graphic representation of a sacred space [1][4]. The experience we developed in the frame of IESP Project led to the design and development of an approach and its software implementation for:

- Analyzing cases of recurrent sigla as cultural indicators of non-verbal communication within their different archaeological contexts. 
- Supporting questions about function and role in the field of sigla and according to a multifaceted perspective that takes into account archaeological data to a larger extent.

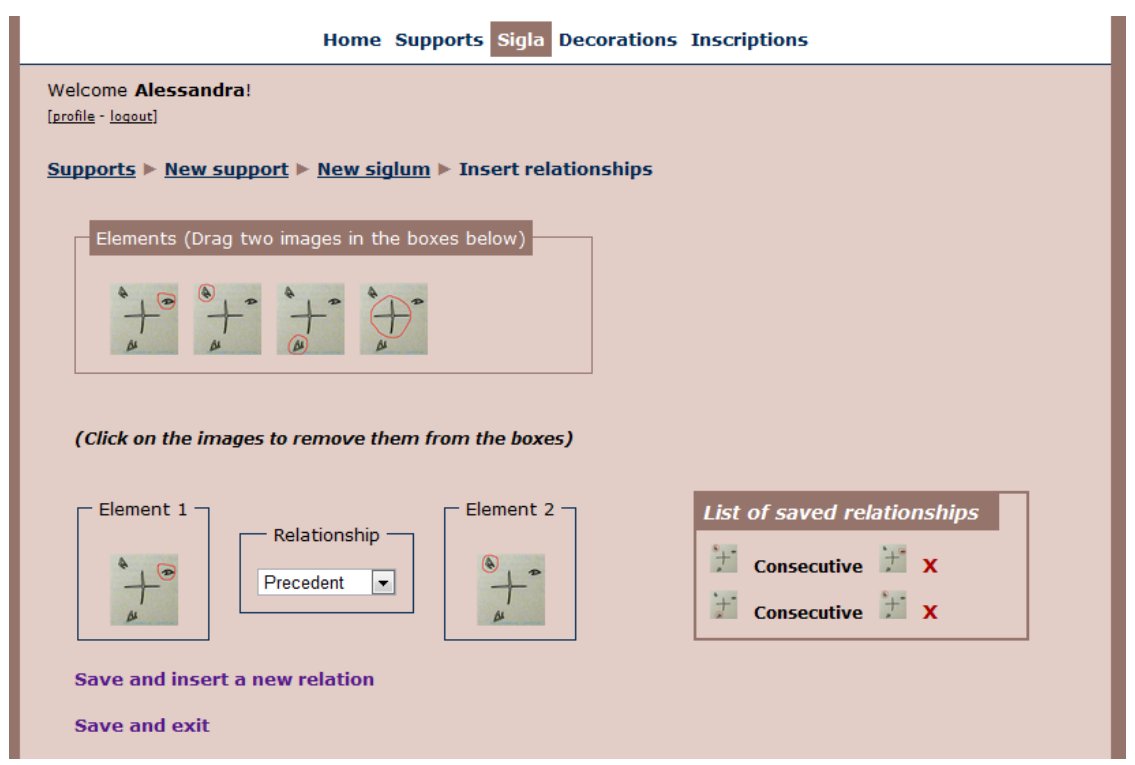

Fig. 6. The IESP System. The archaeologists, using the visual notation they usually adopt on paper, are able to identify relationships between different elements in the same siglum.

The main goal of the approach and the final system is to assess sigla with reference to their geographical range and chronology, to the nature of the objects and contexts to which they belong and to the layout of the graphic design. The enormous amount of data, the variety of the cultural background of archaeological experts involved the wide span of different hypotheses about the interpretation of each siglum type and their relationships led to the design of a tool that supports collaborative activities and dialectic comparisons. In our case, the goal is to interpret the meaning of non-verbal markings by means of the comparison of images, the sharing of descriptions, and the collaborative contribution by whole interdisciplinary team.

\section{$5 \quad$ Innovative SOA architecture for supporting archaeological research}

Now that the main tools required by the team to support their practice have been developed, the need of bridging gaps among them represents the new challenge that we are working on. We are currently working on connecting the tools to integrate archaeological data, artefacts and architectural structures (subsoil and over-ground), cartographic 
and photographic documentation, and scientific content. There is in fact a growing demand for a comprehensive solution in archaeological resources management able to offer a multifaceted and flexible environment for supporting archaeologists' work during all phases of their activities of study.

To this aim, many organizations are looking to cloud computing to reduce their Information Technology costs. Specifically, a cloud-based technology infrastructure is enable the aggregation of digital content and a number of services help to reduce technical, semantic and skills barriers and to render the content more discoverable and interoperable. A cloud of services is definitely needed when no supercomputer or no dedicated hardware infrastructure is available.

Starting from these considerations, the our current activities aim at setting up a cloud platform on top of current public and private repositories (owned by universities, cultural institutions, museums, and archaeological parks either open, private, or subjected to fee). The platform is conceived for extracting and integrating content according to the researchers and scholars' needs, the specific quality criteria, and the sharing policies. The member of the interdisciplinary team of domain experts (archaeologists but also architects, chemists, geologists, anthropologists or others users) are the target of this cloud of service. They are put in the condition to search content to be used either for their personal studies or for supporting their interpretations and ideas in comparison with other colleagues. The idea is to exploit the metaphor of the "Cloud of Services" in order to provide a vision inspired from the Service Oriented Architecture paradigm where services are fully connected to the network and integrated with the cloud. Cloud computing can offer virtually unrestricted capabilities (e.g. storage and processing) to implement services and applications that can exploit data and visualization strategies provided by the cloud of services in different archaeological contexts. The cloud essentially acts as a transparent layer between services and applications providing flexibility and scalability and hiding the complexities between them. The final result is expected to be the development of an innovative authoring Web platform that uses an ontologybased discovery and integration mechanism. The challenge of this environment is to enable the combination of a cloud of services that can support analytical reasoning facilitated by interactive visual interfaces. The design of this ontology is based on our previous research carried in the context of the T.Arc.H.N.A. Project [42]. It will provide a global ontology specifically tailored for the archaeological context able to map concepts and content available in each considered data source in order to establish a kind of lingua franca ${ }^{l}$ among the different services. The aim of this ontology is to offer a way for mapping services in an integrated manner with well-defined semantics. Through the use of this ontology, the platform will build on a Web-mashups strategy able to integrate interactive components (widgets/gadgets), to represent the services coming from the cloud, to create new consistent and value-adding composite applications. To achieve this ambitious result, we plan to use methods and techniques of EndUser Development [5], i.e. a research discipline that studies how to enable users who are not professional developers in create or modify software without forcing them to

1 Bridge language, trade language. 
acquire programming skills. Under this perspective, the platform is designed for supporting the domain experts in detecting, combining, visualizing and analyzing data coming from different services and transforming the data into information, information into knowledge, and knowledge into wisdom. The basic idea aims at enabling domain experts for unwittingly developing personalized mashups according to specific needs via the use of direct manipulation interaction. In Section 4, we presented the tools we developed for supporting the archaeological practice. In what follows, we illustrate the services that are currently under development and that will be integrated in the cloud.

\subsection{Wrapping service for many original data sources}

This service is designed to identify the type and format of archaeological content (but also other related data coming from architectural, geographic, geological, and historical archives) available in each repository. This service provides data at three layers.

The first layer offers an access to the (physical) objects belonging to the different institutions. These can be archaeological artefacts, archived documents, cartographies, chemical/geological analysis results or any other type of item that can be of interest.

The second layer allows to access digital objects that somehow represent the physical objects. These can be photographs, scans, transcriptions, 3D models, videos, audio recordings or any other type of digital file. It is important to note that there can be multiple digital objects relating to one physical object.

In the third layer, the service provides descriptive metadata about the digital objects: information about the digital and physical object and factual information such as titles, authors and dates as well as descriptions and relationships to other objects.

The final output of this service will be a semantic representation of the data coming from the distributed repository defined according to the ontology concepts created for effectively expressing the intrinsic characteristics of a specific archaeological context.

\subsection{Map-based Spatio-Temporal Queries and Data-mining Strategies}

This service, receiving as input a set of data-wrapping services, combined by using the ontology-based integration mechanism, provides data-mining functionality for searching hidden patterns in collection of heterogeneous data and spatio-temporal queries. This service is designed around a set of classical data mining techniques such as anomaly detection (outlier/change/deviation detection), association rule learning (dependency modelling), clustering, classification, regression, and summarization.

The data wrapping service, when combined with a service able to offer detailed information about geographical regions and sites (such as Google Maps), can provide map-based data visualization functionalities in order to exploit the temporal and spatial nature of the integrated data. Several studies and projects [32][36] aim at studying some aspects of the design and implementation of map-based applications for managing, querying and visualizing changing locations of moving objects. By exploiting these studies, this service aims at providing a map-based visualization through which to carry out analysis and monitoring of trajectories of objects discovered in an excavation site. 
These trajectories can concern both documented movements that brought an object towards the place in which it was found, and later movements that brought it from the place where it was discovered to the place where it is preserved. This service will enable to specify typical continuous queries (such as range, distance, and nearest neighbor search) and visual display of objects' trajectories and collection of movement statistics. This service will be endowed with a location intelligence visualization strategy to identify patterns and trends by seeing and analyzing data in a map view with spatial analysis tools such as thematic maps and spatial statistics. This location aware service will help to find data by using spatial relationships to filter relevant data. A temporal condition of this location aware service will be applied for providing spatio-temporal clusters, simulation and visualization, map animation and movement tracking.

\subsection{Social Networks Service}

The service aims at offering a set of functionalities for creating a social network of domain experts, scholars, students, and researchers. It will promote the creation of communities around the knowledge areas and will support their members in all the phases of the creation, revision, audit, and publication of hypothesis, thesis and, interpretations on how and why cultures evolved over time.

Several roles will be established in the social network that will dynamically change, according to the level of participation of the member to the network. This involvement will be stimulate through a set of serious game solutions in order to acquire points and obtain gifts and rewards of users' activities. Moreover, this social network service will be endowed with social computing techniques in order to study social network dynamics and to promote crowd-sourcing analysis that can lead to new and meaningful uses of data. Exploiting models such as pure probabilistic models [30], exponential random graph models [30][34][33][38], and the latent space models [25], we aim at capturing social relationships dynamics among users in order to provide a user with suggestions based on preferences of other users according to their role in each community, their competencies, and their level of participation. In this way, in accessing the archaeological information, users will be guided by suggestions coming from other users taking into account that well-regarded members of the social network will have a higher influence in the whole process.

\subsection{Analysis Support Service}

By exploiting data wrapping services that contain stratigraphic information of excavation sites, this service is devised for supporting the domain experts in analyzing stratigraphies from temporal and spatial points of view, by exploiting the ArchMatrix application described in Section 4. The service aims at providing researchers with a visual representation of the stratigraphic units highlighting geometrical, topological, and temporal relationships. Stratigraphic units are necessary to detect the relative chronological sequence of the entire excavation site but they also produce a number of supplemental data. The idea is to combine the stratigraphic visualization provided by ArchMatrix 
with external services able to retrieve data about landscapes, cartography, mobile findings, and architectonic structures. This solution aims at separating the layer devoted to the visualization of the graph where it is possible to define queries and algorithms able to explore stratigraphic units from the information layer used for retrieving knowledge coming from other excavation databases. Therefore, to support the complex and interdisciplinary decision-making process at the base of the archaeological practice, this service will allow to develop new opportunities for investigation (both individual and collaborative), to increase knowledge, to improve traditional working practices and to develop new ones.

\section{Conclusions and Future Developments}

The aim of our work, and especially the ongoing development of the cloud of services, is to enable interdisciplinary research for supporting archaeological documentation, analysis and dissemination and able to provide an environment for supporting collaboration in this field. This would push forward the boundaries of what semantic and social technologies and Archaeology can do together in order to define original means of communication for practitioners across this field.

In the archaeological literature, the concept of context as an association of objects, which can be physical, spatial and/or temporal, is strictly related to a long archaeological tradition. However, for the renowned French school of anthropology as well as for Anglo-Saxon scholars [24], the concept of pure archaeological context has been supported by the importance of the cultural environment and social structures. Of course, it is nearly impossible to follow such procedures for every category of documentation yielded by an archaeological project without the support of technological solutions and to carry out comparisons with other situations and contexts. Such procedures could be positively supported by adequate graphical environment in which combining different services that aim at helping the archaeologist to verify the validity of their interpretations and studies through sophisticated simulations of the archaeological evidence and data at different scale. The use of a cloud of services and the idea to combine them by using an ontology-based discovery and integration mechanism could be a useful solution. For example, data coming from distributed and heterogeneous databases, 3D reconstructions of archaeological materials and data-mining service could be integrated with landscapes and stratigraphic layers models allowing to combine the aforementioned activities in a unique context of analysis. In such a context, all experts involved in the process of analysis of the results and data from an archaeological project can effectively collaborate to define innovative interpretations and hypotheses. Therefore, the final aim of our current studies and development activities is addressed to explore new strategies for studying interdisciplinary knowledge by means of innovative authoring Web platform able to put together and combine part or all described services characterizing archaeological studies according to their heterogeneous expertise - geologi$\mathrm{cal}$, historical, anthropological, chemical, human, and many others. The platform will build on cutting-edge Rich Internet Application (RIA) and semantic technologies for providing domain experts with a user-centered Web application mashup platform. 


\section{$7 \quad$ References}

1. Bagnasco Gianni, G.: Rappresentazioni dello spazio "sacro" nella documentazione epigrafica etrusca di epoca orientalizzante. In: Raventós, X., Ribichini, S., Verger, S. (eds.) Atti del Convegno Saturnia Tellus, pp. 267-281. Consiglio Nazionale delle Ricerche, Rome (2008)

2. Bagnasco Gianni, G: Tarquinia: Excavations by the University of Milano at the Ara della Regina Sanctuary. In: Edlund-Berry, I.E.M., de Grummond, N.T. (eds.) The Archaeology of Sanctuaries and Ritual in Etruria, JRA 81, pp. 45-54 (2011)

3. Bagnasco Gianni, G.: Tarquinia, Sacred Areas and Sanctuaries on the Civita Plateau and on the Coast: 'monumental complex', Ara della Regina, Gravisca. In: Turfa, J. M. (ed) The Etruscan World, pp. 594-612 (2013)

4. Bagnasco Gianni, G., Gobbi, A., Scoccimarro, N.: Segni eloquenti in necropoli e abitato. In: L'ecriture et l'espace de la mort. Recontres internationales (2009)

5. Barricelli, B. R.: An architecture for End-User Development supporting global communities. PhD dissertation. Advisors: Prof. Ernesto Damiani, Dr. Stefano Valtolina. Università degli Studi di Milano, Italy (2011)

6. Barricelli, B.R., Valtolina, S., Marzullo, M.: ArchMatrix: A Visual Interactive System for Graph-based Knowledge Exploration in Archaeology. In: Proc. AVI 201, pp. 681-684, ACM Press (2012)

7. Bianchi, A., Bottoni P., and Mussio, P.: Issues in Design and Implementation of Multimedia Software Systems. In: Proc. of IEEE International Conference on Multimedia Computing and Systems (ICMCS'99), pp. 91-96 (1999)

8. Bilandzic, M., Venable, J.: Towards participatory action design research: adapting action research and design science research methods for urban informatics. Journal of Community Informatics 7(3) (2011)

9. Bonghi Jovino, M.: The Tarquinia Project: A Summary of 25 Years of Excavation. AJA 114, pp. 161-180 (2010)

10. Bruns, A.: Blogs, Wikipedia, Second Life, and beyond: from production to produsage. Peter Lang Publishing, New York, USA (2008)

11. Costabile, M.F., Fogli, D., Mussio, P., Piccinno, A.: End-user development: the software shaping workshop approach. In: Lieberman, H., Paternò, F., Wulf, V. (eds.) End User Development. Springer-Verlag New York (2006)

12. Crofts, N., Doerr, M., Gill, T., Stead, S., Stiff, M.: Definition of the CIDOC Conceptual Reference Model. http://www.cidoc-crm.org/official_release_cidoc.html.

13. De Souza, C. The Semiotic Engineering of Human-Computer Interaction. The MIT Press (2005)

14. Dittrich, Y.: Computer Anwendungen und sprachlicher Kontext. Zu den Wechselwirkungen zwischen normaler und formaler Sprache bei Einsatz und Entwicklung von Software. PeterLang (1997)

15. Dittrich, Y.: How to Make Sense of Software - Interpretability as an Issue in Design, Technical Report, University of Karlskrona Ronneby (1998)

16. Fischer, G.: End-User Development and Meta-Design: Foundations for Cultures of Participation. J. Organ. End User Comput. 22 (1), pp. 52-82 (2010)

17. Gianni, G.B., Marzullo, M., Valtolina, S., Barricelli, B.R., Bortolotto, S., Favino, P., Garzulino, A., Simonelli, R.: An Ecosystem of Tools and Methods for Archeological Research. In: Proc. VSMM 2012, pp. 133-140, IEEE (2012)

18. Gruber, T.R.: A translation approach to portable ontology specifications. Knowl. Acquis. 5, pp. 199-220 (1993) 
19. Gruber, T.R.: Toward principles for the design of ontologies used for knowledge sharing? International Journal of Human-Computer Studies 43 (5-6), pp. 907-928 (1995)

20. de Grummond, N.T., Bare, C., Meilleur, A.: Etruscan sigla ("graffiti"): Prolegomena and some case studies. Archaeologia Transatlantica 18, pp. 25-38 (2000)

21. Harris, E.C.: Principles of Archaeological Stratigraphy. Academic Press (1979)

22. Herman, I., Melancon, G., Marshall, M.: Graph visualization and navigation in information visualization: A survey Visualization and Computer Graphics. IEEE Transactions on Visualization and Computer Graphics 6 (1), pp. 24-43 (2000)

23. Hix, D., Hartson, H.R.: Developing user interfaces: ensuring usability through product \& process. John Wiley \& Sons, Inc. (1993)

24. Hodder, I.: Archaeological Theory Today. Polity Press (2000)

25. Hoff, P.D., Raftery, A.E., Handcock, M.S.: Latent space approaches to social network analysis. Journal of the American Statistical Association (2002)

26. Lieberman, H., Paternò, F., Wulf, V.: End User Development. Springer-Verlag New York (2006)

27. Marzullo, M.: Spazi sepolti e dimensioni dipinte nelle tombe tarquiniesi. In press.

28. Muller, M.J., Rebecca, C.: Using the CARD and PICTIVE participatory design methods for collaborative analysis. In: Field methods casebook for software design, pp. 17-34. John Wiley \& Sons (1996)

29. Nardi, B., Engeström, Y.: Web on the wind: the structure of invisible work. Computer-Supported Cooperative Work 8(1-2), pp. 1-8 (1999)

30. Newman, M.E.J, Watts, D.J., Strogatz, S.H.: Random graph models of social networks. PNAS 99(1) (2002)

31. Orngreen, R., Pejtersen, A.M., Clemmensen, T.: Themes in Human Work Interaction Design. In: IFIP International Federation for Information Processing, Volume 272, pp. $33-46$ (2008)

32. Osmanovic, D., Meskovic, E.: Visualization of streaming trajectories. In: 37 th International Convention on Information and Communication Technology, Electronics and Microelectronics, MIPRO 2014, Opatija, Croatia, May 26-30, pp. 1633-1637 (2014)

33. Rao, M., Gadia, D, Valtolina, S., Bagnasco, G., Marzullo, M.: Designing Virtual Reality reconstructions of etruscan painted tombs. In: Multimedia for Cultural Heritage (First International Workshop on Multimedia for Cultural Heritage - revised selected papers), Springer Communications in Computer and Information Science 247(3), pp. 154-165 (2012)

34. Robins, G., Snijders, T., Wang, P., Handcock, M., Pattison, P.: Recent developments in exponential random graph $(<\mathrm{i}>\mathrm{p}</ \mathrm{i}>*)$ models for social networks, Social Network 29 (2007)

35. Shan, J., Toth, C.K.: Topographic laser ranging and scanning. Principles and Processing. CRC Press (2008)

36. Schneider, M.: Spatial and spatio-temporal data models and languages. In: Encyclopedia of Database Systems, pp. 2681-2685 (2009)

37. Schön, D.: The Reflective Practitioner: How Professionals Think in Action. Maurice Temple Smith (1983)

38. Snijders, T.A.B.: Markov Chain Monte Carlo Estimation of Exponential Random Graph Models. CMU Journal of Social Structure 3 (2002)

39. Snow, C.P.: The Two Cultures and the Scientific Revolution. Cambridge University Press (1959)

40. Valtolina, S., Barricelli, B.R., Bagnasco, G., Bortolotto, S.: ArchMatrix: Knowledge Management and Visual Analytics for Archaeologists. In: Proc. HCI 2013, pp. 258-266, LNCS 8018, Springer (2013) 
41. Valtolina, S., Barricelli, B.R., Dittrich, Y.: Participatory Knowledge-Management Design: a Semiotic Approach. Journal of Visual Languages and Computing (JVLC), 23(2), pp. 103-115 (2011)

42. Valtolina, S., Mussio, P., Bagnasco, G., Mazzoleni, P., Franzoni, S., Geroli, M., Ridi, C.: Media for knowledge creation and dissemination: semantic model and narrations for a new accessibility to cultural heritage. In: Proceedings of the 6th ACM SIGCHI Conference on Creativity \& Cognition (C\&C’07), pp. 107-116, ACM Press (2007) 